\title{
Mentored training and its association with dissemination and implementation research output: a quasi-experimental evaluation
}

\author{
Rebekah R Jacob ( $\square$ rebekahjacob@wustl.edu ) \\ Washington University in Saint Louis https://orcid.org/0000-0003-2466-8809 \\ Angeline Gacad \\ Washington University in Saint Louis \\ Margaret Padek \\ Washington University in Saint Louis \\ Graham A Colditz \\ Washington University in Saint Louis \\ Karen M Emmons \\ Harvard University T H Chan School of Public Health \\ Jon F Kerner \\ Canadian Partnership Against Cancer (retired) \\ David A Chambers \\ National Institutes of Health/National Cancer Institute \\ Ross C Brownson \\ Washington University in Saint Louis
}

\section{Short report}

Keywords: Evaluation, Dissemination and Implementation, Scientific Productivity, Dissemination and Implementation Research Training

Posted Date: April 24th, 2020

DOI: https://doi.org/10.21203/rs.2.23698/v2

License: (9) (i) This work is licensed under a Creative Commons Attribution 4.0 International License. Read Full License

Version of Record: A version of this preprint was published at Implementation Science on May 11th, 2020. See the published version at https://doi.org/10.1186/s13012-020-00994-0. 


\section{Abstract}

Background There is continued need to evaluate training programs in dissemination and implementation (D\&l) research. Scientific products yielded from trainees are an important and objective measure to understand capacity growth within the D\&l field. This study evaluates our mentored training program in terms of scientific productivity among applicants.

Methods Post-doctoral and early career cancer researchers were recruited and applied to the R25 Mentored Training for Dissemination and Implementation Research in Cancer (MT-DIRC) between 2014 and 2017. Using application details and publicly available bibliometric and funding data, we compared selected fellows with unsuccessful applicants (nonfellows). We extracted Scopus citations and US federal grant funding records for all applicants $(\mathrm{N}=102)$. Funding and publication abstracts were de-identified and coded for D\&I focus and aggregated to the applicant level for analysis. Logistic regression models were explored separately for the odds of 1) a D\&I publication and 2) US federal grant funding post year of application among fellows ( $\mathrm{N}=55)$ and nonfellows ( $\mathrm{N}=47)$. Additional models were constructed including independent variables that attenuated the program's association by 5 percent or more. Only US-based applicants $(\mathrm{N}=87)$ were included in grant funding analysis.

Results Fellows and nonfellows were similar across several demographic characteristics. Fellows were more than 3 times more likely than nonfellows to have grant funding after MT-DIRC application year (OR 3.2; 95\% Cl: 1.1-11.0) while controlling for time since application year; the association estimate was 3.1 (95\% Cl: 0.98-11.0) after adjusting for both cancer research area and previous grant funding. For publications, fellows were almost 4 times more likely to publish D\&I focused work adjusting for time (OR 3.8; $95 \% \mathrm{Cl}$ : 1.7-9.0). This association lessened after adjusting for previous D\&I publication and years since undergraduate degree (OR 2.9; $95 \% \mathrm{Cl}: 1.2-7.5)$.

Conclusions We document the association of a mentored training approach with built-in networks of peers to yield productive D\&I researchers. Future evaluation efforts could be expanded to include other terms of longer-term productivity such as policy or practice change as additional objective measures. D\&I research trainings in the US and internationally should consider common evaluation measures.

\section{Background}

\section{Contributions to the literature}

- The number of trainings in dissemination and implementation (D\&l) continues to expand globally. Few D\&I training evaluations are published and those evaluations reported tend to be small-scale and short term with limited measures of impact.

- This study reports that our training program enhances academic productivity and highlights that mentored training for D\&l scholars is an essential approach for building capacity for D\&I research.

- Using publicly available data, the methods in this study could be replicated with other D\&I trainings to compare impact across fields.

Growing the field of dissemination and implementation (D\&l) research and the next generation of individuals to lead it are high priorities $(1,2)$. These goals have been supported recently by several training programs across the globe which provide researchers with a solid foundation in approaches to close the gap between scientific discovery and practice. The programs vary in breadth and focus (mental health, cancer, etc.) as well as format (in-person, web-based, etc.) and content delivery components (didactic, on-site visits, mentoring, etc.) (3-14).

Much of what we know about the potential benefits of these trainings is from examining how participants fared after the training either by comparing pre-post knowledge or competency needed to grow the D\&I field. However, few D\&I training programs have examined the trajectory of the training participant with respect to peers who did not receive the same training. Typically, training programs are not randomized by design and understanding effects is challenging. Recently, two D\&l training 
programs introduced unsuccessful applicants as a comparison group to evaluate research productivity resulting from program participation. The evaluation of the Training Institute for Dissemination and Implementation Research in Health (TIDIRH) combined cross-sectional surveys of past fellows with portfolio analysis of grants submitted and funded (15). In addition, the mental health-focused Implementation Research Institute (IRI) program studied bibliometric outcomes among fellows and non-selected applicants (16). Other academic training efforts have also begun to take advantage of the growing availability of publicly available research product information $(17,18)$. Such studies pave the way for meaningful understanding of associations between mentored training and scientific productivity. The previous studies also provide valuable insights to funders, especially within the context of learning how best to train and build capacity for a newer field such as D\&I science.

The Mentored Training for Dissemination for Implementation Research in Cancer (MT-DIRC) has trained and mentored over 50 junior to mid-level career researchers to increase their knowledge of and capacity for D\&l research in cancer. The training increased D\&I research competencies from pre to six-and 18-months post their initial training (6). The purpose of this study is to examine the program's association with capacity building for D\&I research, specifically in the areas of publishing and acquiring US Federal Grant funding for D\&I research.

\section{Methods}

This study used a quasi-experimental design (pre/post with comparison group) to examine the relationship of the MT-DIRC training program with subsequent scholarly output in the form of D\&I related publications and US Federal funding secured for research. Our main research question sought to determine if there was a difference among fellows vs. nonfellows in likelihood to produce research outputs after participation (vs. nonparticipation) in the program.

Training program description summary. The MT-DIRC training was an R25 mentored training program funded by NCl (PAR-12049) to increase capacity for D\&I research related to the spectrum of cancer control (etiology to survivorship) (19). The full description of the program is published with preliminary results on skill building (6). Here we provide a brief summary of the program.

Eligibility requirements included a doctorate degree and full-time appointment in a research setting. Recruitment through various listservs and advertisement at D\&I related events and conferences focused mostly on early-career researchers or midto-late career researchers looking to shift the focus of their work to D\&I research. To apply, researchers submitted an informational cover page, concept paper for a D\&I study to work on during the program, biosketch, and two letters of reference. Program faculty rated each application based on several areas including overall application quality, commitment to D\&l research, experience working in trans-disciplinary networks, research support and potential, likelihood for career development, appropriate methods in concept paper, appropriate topic in concept paper, and potential impact of the work proposed.

Selected applicants participated in two Summer Institutes (5-day trainings) in St. Louis, Missouri, USA each June. Trainings primarily focused on competencies for D\&I research (20) and in-person mentoring and interactive sessions to work on and receive feedback related to research proposals and or other projects in progress. Ongoing evidence-informed mentoring (21), often in the form of regularly scheduled calls, continued for two years. Fostering collaboration among the program's network of fellows and mentors was a concerted focus of the program. All current and past fellows and mentors were invited to participate in quarterly webinars and to attend annual meet-up events at the D\&l science conference in Washington, DC.

Data collection and processing. In total, 105 applicants applied to the program between 2014 and 2017. Three who were selected into the program later dropped out for various career/personal reasons and were excluded from this study. The total sample of program applicants included in this study is 102: 55 that were selected and participated in the MT-DIRC program ("fellows") and 47 unselected applicants ("nonfellows") as comparison group. Demographic information data was collected from each application.

For information on scholarly output, two main sources of publicly available data were used. To gather all published works, we utilized Scopus (www.scopus.com), a comprehensive citation database with over 75 million records (22). All applicants to the 
MT-DIRC program were searched in the Scopus database and after verifying academic affiliation, their citations and accompanying abstracts were extracted through Scopus's BibTeX export tool in July 2019 and further processed in R using the 'bibliometrix' package (2.3.2) (23). A total of 5,189 publication citations were extracted. Initially, $11 \%(\mathrm{~N}=565)$ were missing abstracts. Upon closer examination, certain article types were responsible for much of the missing abstracts and were necessary to exclude (Erratums $=30$, Notes $=208$, Letters $=129)$. For the remaining with missing abstracts $(\mathrm{N}=258)$, a member of the research team searched each citation to confirm missing abstracts (e.g. some journals do not require) or extract the abstract if found. A total 208 additional abstracts were located and remaining citations without abstracts $(\mathrm{N}=50)$ were excluded. The final dataset contained 4,772 citations and included only citation ID number, applicant ID number, title, and abstract for further de-identified coding.

To gather grant funding, we used the National Institutes of Health's $(\mathrm{NIH})$ Research Portfolio Online Reporting Tools (RePORTER Tool Manual, 2018). RePORTER is an electronic tool to search the US federal repository of intramural and extramural $\mathrm{NIH}$-funded research projects dating back to 1985. The repository also includes funded projects by the Administration for Children and Families (ACF), the Agency for Healthcare Research and Quality (AHRQ), the Centers for Disease Control (CDC), the Health Resources and Services Administration (HRSA), the Food and Drug Administration (FDA) and the Department of Veteran Affairs (VA). The R package 'fedreporter' (0.2.1) (24) was used to extract grant funding information from RePORTER's application programming interface (API) including abstracts for all applicants in September 2019. We included records where the applicant was either a coinvestigator or a principal investigator. A total of $N=271$ funding records were extracted. After keeping the first fiscal year of duplicate entries (e.g. multi-year funding) the total sample of unique US federally funded projects was $\mathrm{N}=97$. Funding cases were reduced to grant ID, applicant ID, title, and abstract for further de-identified coding.

\section{Coding process}

For each publication and grant abstract, D\&I focus was coded as "yes" or "no" similar to Baumann and colleagues criterion (16). D\&l focus "yes" included an "implementation-centered hypothesis, design, or framework, focused on assessing the implementation climate of an organization, or described the implementation processes for a particular intervention." For example, abstracts which explicitly examined implementation outcomes were coded as "yes" and those that focused only on intervention outcomes were coded as "no". In addition, all publications featured in the Implementation Science journal were coded as D\&I "yes" based upon the journal's inherent D\&I focus and scope. Two project staff (RRJ, AG) coded publication and grant abstracts. For publications, an initial random selection of citations $(\mathrm{N}=20)$ were double coded by both project staff and discussed to reach agreement on inclusion and exclusion criteria before proceeding with single coding by one coder (AG) for remaining citations. A random sample of $10 \%$ was selected for double coding and showed a $93 \%$ agreement. The number of grants was considerably less than the total number of publications and therefore all were double coded with any discrepancies reconciled to reach $100 \%$ consensus.

\section{Data Analysis}

After coding was complete on each publication and grant, data were aggregated to the applicant level and merged with applicant demographic data for analysis $(\mathrm{N}=102)$. Because RePORTER is solely for US based research, we excluded foreign applicants $(\mathrm{N}=15)$ from grant analyses.

We compared demographic, publication, and funding data by applicant status with independent samples t-tests (continuous data), and chi-square tests (categorical data). For modeling, two main binary outcomes were examined: any D\&I publication after application year (yes or no), and because the program supported grant writing in general, "any" grant funding after application year (yes or no). Binary logistic regression models examined program status with each outcome. Attenuation or change in estimates (CIE) of program participation resulting from the inclusion of independent variables was examined (25, 26). Variables which resulted in more than $5 \%$ attenuation were included in separate and combined models for further examination. All analyses were completed in R (27) with an alpha level set at 0.05 . 


\section{Results}

Fellows and nonfellows were similar across several demographic characteristics (Table 1). The majority were female (80.4\%) and "prevention" was the most common cancer research area focus (48.0\%). Assistant professor was the largest category of position among applicants (46.1\%) followed by post-doc or research scientist (21.6\%), other (17.6\%) and associate professor or professor $(14.7 \%)$. On average, applicants were $17.9(\mathrm{SD}=6.7)$ years post undergraduate degree when they applied for the MT-DIRC program.

Fellows and nonfellows differed in grant funding before their application year (51.0\% vs. $34.2 \%)$, and fellows were more likely to have grant funding following the application year (36.7\% vs. $13.2 \%)$ (Table 2). Before and after application year, fellows were more likely to have a D\&I publication than nonfellows (36.4\% vs. $14.9 \%$; $65.5 \%$ vs. $31.9 \%)$. These differences were accounted for in mutivariate analyses that follow.

Table 3 shows that fellows were more than three times more likely than nonfellows to have grant funding after the MT-DIRC application year (OR 3.2; 95\% Cl: 1.1-11.0, Model 1) while controlling for time since application year. Effect estimates were 3.3 (95\% Cl: 1.1-11.6, Model 2), adjusting for cancer research area, 3.0 (95\% Cl: 0.99-10.2, Model 3) adjusting for previous grant funding and 3.1 (95\% Cl: 0.98-11.0, Model 4) after adjusting for both cancer area and previous grant funding.

Table 4 shows that fellows were almost four times more likely to publish D\&l focused work compared to nonfellows while adjusting for time (OR 3.8, 95\% Cl: 1.7-9.0, Model 1). Odds remained elevated for fellows after additionally adjusting for previous D\&I publication (OR 3.1, 95\% Cl: 1.3-7.7), Model 2), years since undergraduate degree (OR 3.5, 95\% Cl: 1.5-8.8, Model 3 ), and both D\&I publication and years since undergraduate degree (OR 2.9, 95\% Cl: 1.2-7.5, Model 4).

\section{Discussion}

Overall our results show that, in general, fellows were more likely than nonfellows to contribute to the D\&I research literature following their participation in the MT-DIRC program.

Our findings are similar to the evaluation study of a mentored implementation science training in mental health where fellows were more likely to receive D\&I grants and publish D\&I work post fellowship (16). Comparatively, selected fellows to MT-DIRC were less experienced in D\&I with fewer D\&I pubs (36\% vs. 67\%) and D\&I funding (16\% vs 36\%) at baseline than IRI fellows. Unlike the IRI program, MT-DIRC did not require experience writing NIH grants as a prerequisite, which might account for this difference. Nonetheless, both studies point to the career impact and potential for D\&I research capacity growth within the field through multi-year, mentored training approaches.

Globally, several training programs aim to build capacity for translational research (translating research to practice and communities). A recent synthesis of US and international of D\&I research trainings describe a large range in approaches, ranging from single short courses to long term academies that combine didactic training with mentoring (8). Training endeavors have contributed to the field with evaluation findings, though common metrics are lacking and could aid in understanding trainings' collective impact on capacity building. In addition, understanding training outputs (outcomes) based upon training inputs (e.g., frequency, length, format) could identify "active ingredients" for the largest impact. Here we provide a fairly simple template with publicly available data to understand training impact on scientific productivity in the field. Attention from the field is needed to develop templates for other impacts or common measures (knowledge, networking, mentoring) from D\&I research training programs. Our program also conducted qualitative interviews with fellows to understand how specific activities within the program may have affected these measures (analyses in process). Combined evaluation approaches are likely needed to fully understand impacts of specific program activities on research outputs.

One byproduct of mentored training approaches is the network of peers and mentors which has been linked to increased research collaborations (28). Building and fostering collaborations within this network was a main objective of the MT-DIRC mentored approach to training and may have attributed to the increased scientific productivity of our fellows. Guise and colleagues qualitative evaluation with mentors and mentees suggests team mentoring "works when" mentors and mentees 
bring varying perspectives and expertise and when mentors promote networking among mentees (29). At the 5-day in-person Summer Institute, fellows at various intersections of D\&I cancer prevention and control research connected and organized manuscripts to address gaps in the science. These collaborative publications were also supported and encouraged through inperson mentoring and group mentoring calls. Group mentoring provided a platform to interact with like-minded peers, a dedicated space for critique by experts in the field, and a continuous longer-term relationship with peers and mentors that likely aided fellows in accelerating their research progress.

Generating manuscripts is often accomplished in a shorter time frame in comparison to the process of proposing and receiving competitive grant funding. At the time of this study, it has been five years since the first cohort attended their first Summer Institute. Producing and disseminating key research in D\&I is an important step to increase knowledge and fill gaps of understanding. This speaks to the potential of a mentored training program to accelerate D\&I capacity building at relatively rapid pace, which is needed to continue to build the field.

\section{Limitations}

While our study provides one approach to understanding of the relation between mentored training and building capacity in D\&I research, several limitations should be noted. A main limitation is the use of unsuccessful applicants as a control group. While we provide data to show the groups were statistically similar across several characteristics, there may be unmeasured differences that led fellows to be selected at the outset. An example of this could be applicant selection criteria of research support and potential and likelihood for career development. We did not account for research funding trends which may have given priority for some applicants and not others. We also did not include journal impact measures for citations, a potential factor for understanding research impact. Our six-year funding period is a function of a grant cycle, and too short for understanding longer-term effects on practice and policy. Easy access to comprehensive productivity information is limited mostly to publications and databases of federal funding. Understanding other forms of productivity like changes to cancer control policy or practice based on D\&I research and spreading D\&I research capacity through teaching and presenting would be ideal for a fuller understanding of impact. This would require standardized metrics and measures.

\section{Conclusions}

Mentored training is an important and effective approach to building capacity in D\&I research. A growing body of literature shows the value of systematic approaches to mentored training in biomedical research (21), and specifically in D\&I research (16). Our evaluation and other recent literature highlight the combined impacts of didactic teaching, networking, and mentoring. This study used one evaluation approach to examine scientific productivity and additional steps are needed (e.g., stronger evaluation designs, standardized metrics and measures) to fully document training program impacts.

\section{List Of Abbreviations}

MT-DIRC- Mentored Training for Dissemination and Implementation Research in Cancer

D\&I- Dissemination and Implementation

\section{Declarations}

\section{Declarations}

Not applicable.

\section{Ethics approval and consent to participate}

Ethics approval was obtained the Washington University in St. Louis Institutional Review Board (\#201303122). 


\section{Consent for publication}

Not applicable.

\section{Availability of data and material}

The datasets analyzed during the current study are available from the corresponding author upon reasonable request.

\section{Competing interests}

Authors have no competing interests to declare.

\section{Funding}

This work was supported by the National Cancer Institute at the National Institutes of Health (grant numbers 5R25CA171994, P30CA09184, P50CA244431); the US Department of Veterans Affairs; the Cancer Research Network; the National Institute of Diabetes and Digestive and Kidney Diseases at the National Institutes of Health (grant number P30DK092950); the Centers for Disease Control and Prevention (grant number U48DP006395). The findings and conclusions in this paper are those of the authors and do not necessarily represent the official positions of the National Institutes of Health, the Department of Veterans Affairs, or the Centers for Disease Control and Prevention.

\section{Authors' contributions}

Conceptualization and design: RRJ, RCB. Data abstraction, management and analyses: RRJ, ACD. Manuscript development and revisions: All. All authors read and approved the final manuscript.

\section{Acknowledgements}

We acknowledge the administrative support of Linda Dix, Mary Adams, Cheryl Valko and research assistant support of students Romario Smith and Emily Weno-Rodriguez at the Prevention Research Center in St. Louis, Brown School, Washington University in St. Louis. We thank Matthew Kreuter, Shiriki Kumanyika, Maureen Dobbins, Enola Proctor, Anne Sales, Kurt Stange, and Debra Haire-Joshu for their contribution as core faculty members to the MT-DIRC program. We also acknowledge the expertise in mentoring provided by Christine Pfund and the statistical expertise provided by Bobbi Carothers.

\section{References}

1. National Cancer Institute: RFA-CA-19-005. Implementation Science for Cancer Control: Developing Centers 2018. https://grants.nih.gov/grants/guide/rfa-files/RFA-CA-19-005.html. Accessed 21 Jan 2020.

2. National Cancer Institute. RFA-CA-19-006. Implementation Science for Cancer Control: Advanced Centers 2018. https://grants.nih.gov/grants/guide/rfa-files/RFA-CA-19-006.html. Accessed 21 Jan 2020.

3. Meissner HI, Glasgow RE, Vinson CA, Chambers D, Brownson RC, Green LW, et al. The US training institute for dissemination and implementation research in health. Implement Sci. 2013;8.

4. Proctor EK, Landsverk J, Baumann AA, Mittman BS, Aarons GA, Brownson RC, et al. The implementation research institute: training mental health implementation researchers in the United States. Implement Sci. 2013;8.

5. Carlfjord S, Roback K, Nilsen P. Five years' experience of an annual course on implementation science: an evaluation among course participants. Implement Sci. 2017;12.

6. Padek M, Mir N, Jacob RR, Chambers DA, Dobbins M, Emmons KM, et al. Training scholars in dissemination and implementation research for cancer prevention and control: a mentored approach. Implement Sci. 2018;13.

7. Moore JE, Rashid S, Park JS, Khan S, Straus SE. Longitudinal evaluation of a course to build core competencies in implementation practice. Implement Sci. 2018;13. 
8. Chambers DA, Proctor EK, Brownson RC, Straus SE. Mapping training needs for dissemination and implementation research: lessons from a synthesis of existing D\&l research training programs (vol 7, pg 593, 2017). Transl Behav Med. 2017;7(3):593-601.

9. Kho ME, Estey EA, DeForge RT, Mak L, Bell BL. Riding the knowledge translation roundabout: lessons learned from the Canadian Institutes of Health Research Summer Institute in knowledge translation. Implement Sci. 2009;4.

10. Morrato EH, Rabin B, Proctor J, Cicutto LC, Battaglia CT, Lambert-Kerzner A, et al. Bringing it home: expanding the local reach of dissemination and implementation training via a university-based workshop. Implement Sci. 2015;10.

11. Norton WE. Advancing the science and practice of dissemination and implementation in health: A novel course for public health students and academic researchers. Public Health Rep. 2014;129(6):536-42.

12. Straus SE, Brouwers M, Johnson D, Lavis JN, Legare F, Majumdar SR, et al. Core competencies in the science and practice of knowledge translation: description of a Canadian strategic training initiative. Implement Sci. 2011;6.

13. University of Massachusettes Medical School. PRACCTIS- Prevention and Control of Cancer: Training for Change in Individual Systems. https://www.umassmed.edu/pracctis/. Accessed 16 Jan 2020.

14. Gonzales R, Handley MA, Ackerman S, O'Sullivan P S. A framework for training health professionals in implementation and dissemination science. Acad Med. 2012;87(3):271-8.

15. Vinson CA, Clyne M, Cardoza N, Emmons KM. Building capacity: a cross-sectional evaluation of the US Training Institute for Dissemination and Implementation Research in Health. Implement Sci. 2019;14(1).

16. Baumann AA, Carothers BJ, Landsverk J, Kryzer E, Aarons GA, Brownson RC, et al. Evaluation of the Implementation Research Institute: Trainees' publications and grant productivity. Adm Policy Ment Hlth. 2019.

17. Jacob BA, Lefgren L. The impact of $\mathrm{NIH}$ postdoctoral training grants on scientific productivity (vol 40, pg 864, 2011). Res Policy. 2012;41(2):864-874.

18. Kasabwala K, Morton CM, Svider PF, Nahass TA, Eloy JA, Jackson-Rosario I. Factors influencing scholary impact: Does urology fellowship training affect research output? J Surg Educ. 2014;71(3):345-52.

19. National Cancer Institute. Cancer Control Continuum. https://cancercontrol.cancer.gov/od/continuum.html. Accessed 8 Jan 2020.

20. Padek M, Colditz G, Dobbins M, Koscielniak N, Proctor EK, Sales AE, et al. Developing educational competencies for dissemination and implementation research training programs: an exploratory analysis using card sorts. Implement Sci. $2015 ; 10$.

21. Pfund C, House SC, Asquith P, Fleming MF, Buhr KA, Burnham EL, et al. Training mentors of clinical and translational research Scholars: A randomized controlled trial. Acad Med. 2014;89(5):774-82.

22. Scopus.

https://www.elsevier.com/_data/assets/pdf_file/0017/114533/Scopus_GlobalResearch_Factsheet2019_FINAL_WEB.pdf. Accessed 21 Jan 2020.

23. Aria MC, C. bibliometrix: An R-tool for comprehensive science mapping analysis. Journal of Informetrics. 2017;11(4):95975.

24. Muschelli J. fedreporter: Interface to Federal 'RePORTER' API. R package version 0.2.1. 2017.

25. Greenland S. Modeling and variable selection in epidemiologic analysis. Am J Public Health. 1989;79(3):340-9.

26. Greenland S, Pearce N. Statistical foundations for model-based adjustments. Annu Rev Publ Health. 2015;36:89-108.

27. Team RC. R: A language and environment for statistical computing. Vienna, Austria: R Foundation for Statistical Computing; 2019.

28. Luke DA, Baumann AA, Carothers BJ, Landsverk J, Proctor EK. Forging a link between mentoring and collaboration: a new training model for implementation science. Implement Sci. 2016;11.

29. Guise JM, Geller S, Regensteiner JG, Raymond N, Nagel J, Car BIR. Team mentoring for interdisciplinary team science: Lessons from k12 scholars and directors. Acad Med. 2017;92(2):214-21. 
Tables

Table 1. Applicant characteristics $(\mathrm{N}=102)$, Mentored Training for Dissemination and Implementation Research in Cancer.

\begin{tabular}{|c|c|c|c|c|}
\hline & Total $(\mathrm{N}=102)$ & Fellow $(\mathrm{N}=55)$ & Nonfellow $(\mathrm{N}=47)$ & \\
\hline & $\mathrm{N}(\%)$ & $\mathrm{N}(\%)$ & $\mathrm{N}(\%)$ & $\mathrm{p}$ value \\
\hline Gender & & & & 0.914 \\
\hline - Female & $82(80.4)$ & $44(80.0)$ & $38(80.9)$ & \\
\hline Cancer area focus & & & & 0.457 \\
\hline - $\quad$ Detection & $16(15.7)$ & $11(20.0)$ & $5(10.6)$ & \\
\hline - $\quad$ Treatment & $19(18.6)$ & $9(16.4)$ & $10(21.3)$ & \\
\hline Position & & & & 0.475 \\
\hline - Associate professor or professor & $15(14.7)$ & $10(18.2)$ & $5(10.6)$ & \\
\hline - $\quad$ Assistant professor & $47(46.1)$ & $27(49.1)$ & $20(42.6)$ & \\
\hline - Post-doc or research fellow & $22(21.6)$ & $10(18.2)$ & $12(25.5)$ & \\
\hline Years from undergraduate degree at time of application; Mean (SD) & $17.85(6.69)$ & $18.21(6.31)$ & $17.422(7.16)$ & 0.565 \\
\hline Application year (Cohort) & & & & 0.011 \\
\hline - $\quad 2014$ & $21(20.6)$ & $13(23.6)$ & $8(17.0)$ & \\
\hline-2015 & $22(21.6)$ & $15(27.3)$ & 7 (14.9) & \\
\hline$-\quad 2016$ & $18(17.6)$ & $13(23.6)$ & $5(10.6)$ & \\
\hline - $\quad 2017$ & $41(40.2)$ & $14(25.5)$ & $27(57.4)$ & \\
\hline
\end{tabular}

${ }^{\mathrm{a} P}$ values from independent samples t tests for continuous data and Pearson Chi-square tests for categorical data.

Table 2. Applicant funding and publication $(\mathrm{N}=102)$, Mentored Training for Dissemination and Implementation Research in Cancer.

\begin{tabular}{|c|c|c|c|c|}
\hline & $\begin{array}{c}\text { Total } \\
(\mathrm{N}=87)\end{array}$ & Fellow $(\mathrm{N}=49)$ & Nonfellow $(\mathrm{N}=38)$ & p value ${ }^{a}$ \\
\hline \multicolumn{5}{|l|}{ Grant funding in RePORTER (US Applicants Only, N=87) } \\
\hline \multicolumn{5}{|l|}{ Before or at application year: } \\
\hline Grant funding; N (\%) & & & & 0.117 \\
\hline - No & $49(56.3)$ & $24(49.0)$ & $25(65.8)$ & \\
\hline - Yes & $38(43.7)$ & $25(51.0)$ & $13(34.2)$ & \\
\hline D\&I grant funding; N (\%) & & & & 0.009 \\
\hline - No & $79(90.8)$ & $41(83.7)$ & $38(100.0)$ & \\
\hline - Yes & $8(9.2)$ & $8(16.3)$ & $0(0.0)$ & \\
\hline \multicolumn{5}{|l|}{ After $^{\mathrm{b}}$ application year: } \\
\hline Grant funding; N (\%) & & & & 0.013 \\
\hline - No & $64(73.6)$ & $31(63.3)$ & $33(86.8)$ & \\
\hline - Yes & $23(26.4)$ & $18(36.7)$ & $5(13.2)$ & \\
\hline D\&I grant funding; N (\%) & & & & 0.042 \\
\hline - No & $75(86.2)$ & $39(79.6)$ & $36(94.7)$ & \\
\hline - Yes & $12(13.8)$ & $10(20.4)$ & $2(5.3)$ & \\
\hline Publications indexed in SCOPUS (all applicants, N=102) & Total $(\mathrm{N}=102)$ & Fellow $(\mathrm{N}=55)$ & Nonfellow $(\mathrm{N}=47)$ & $\mathrm{p}$ value \\
\hline \multicolumn{5}{|l|}{ Before or at application year: } \\
\hline D\&I publication & & & & 0.014 \\
\hline - No & $75(73.5)$ & $35(63.6)$ & $40(85.1)$ & \\
\hline - Yes & $27(26.5)$ & $20(36.4)$ & $7(14.9)$ & \\
\hline \multicolumn{5}{|l|}{ After ${ }^{C}$ application year: } \\
\hline Published D\&I after* application & & & & $<0.001$ \\
\hline - No & $51(50.0)$ & $19(34.5)$ & $32(68.1)$ & \\
\hline - Yes & $51(50.0)$ & $36(65.5)$ & $15(31.9)$ & \\
\hline
\end{tabular}

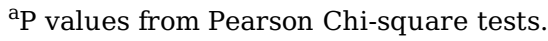

${ }^{\mathrm{b}}$ After represents the time between application year and September 2019 when data was collected. 
${ }^{\mathrm{c}}$ After represents the time between application year and July 2019 when data was collected.

Table 3. US applicant awarded federally funded grant between application year and September 2019 (N=87).

\begin{tabular}{|c|c|c|c|c|c|c|c|c|}
\hline & Model & & Model 2 & & Model & & Model & \\
\hline & b (SE) & $\begin{array}{l}\text { OR }(95 \% \\
\text { CI) }\end{array}$ & b (SE) & $\begin{array}{l}\text { OR }(95 \% \\
\text { CI) }\end{array}$ & b (SE) & OR $(95 \% \mathrm{CI})$ & b (SE) & OR $(95 \% \mathrm{CI})$ \\
\hline \multicolumn{9}{|c|}{$\begin{array}{l}\text { MT-DIRC } \\
\quad \text { Nonfellow (ref) }\end{array}$} \\
\hline Fellow & $\begin{array}{l}1.2 \\
(0.6)\end{array}$ & $\begin{array}{l}3.2(1.1- \\
11.0)\end{array}$ & $1.2(0.6)$ & $\begin{array}{l}3.3(1.1- \\
11.6)\end{array}$ & $\begin{array}{l}1.1 \\
(0.6)\end{array}$ & $\begin{array}{l}3.0(0.99- \\
10.2)\end{array}$ & $\begin{array}{l}1.1 \\
(0.6)\end{array}$ & $\begin{array}{l}3.1(0.98- \\
11.0)\end{array}$ \\
\hline Time & $\begin{array}{l}0.3 \\
(0.2)\end{array}$ & $\begin{array}{l}1.4(0.9- \\
2.1)\end{array}$ & $0.4(0.2)$ & $\begin{array}{l}1.5(0.9- \\
2.4)\end{array}$ & $\begin{array}{l}0.3 \\
(0.2)\end{array}$ & $\begin{array}{l}1.4(0.9- \\
2.1)\end{array}$ & $\begin{array}{l}0.40 \\
(0.2)\end{array}$ & $\begin{array}{l}1.5(0.96- \\
2.4)\end{array}$ \\
\hline \multicolumn{9}{|c|}{$\begin{array}{l}\text { Cancer research } \\
\text { area } \\
\quad \text { Treatment (ref) }\end{array}$} \\
\hline Survivorship & & & $\begin{array}{l}-0.9 \\
(0.86)\end{array}$ & $\begin{array}{l}0.4(0.1- \\
2.0)\end{array}$ & & & $\begin{array}{l}-0.8 \\
(0.9)\end{array}$ & $0.5(0.1-2.6)$ \\
\hline Detection & & & $\begin{array}{l}-0.8 \\
(0.85)\end{array}$ & $\begin{array}{l}0.5(0.1- \\
2.4)\end{array}$ & & & $\begin{array}{l}-0.7 \\
(0.9)\end{array}$ & $0.5(0.1-2.6)$ \\
\hline Prevention & & & $\begin{array}{l}-1.1 \\
(0.71)\end{array}$ & $\begin{array}{l}0.3(0.1- \\
1.3)\end{array}$ & & & $\begin{array}{l}-1.1 \\
(0.7)\end{array}$ & $0.3(0.1-1.3)$ \\
\hline \multicolumn{9}{|l|}{$\begin{array}{l}\text { Previous grant } \\
\text { funding }\end{array}$} \\
\hline $\begin{array}{l}\text { No (ref) } \\
\text { Yes }\end{array}$ & & & & & $\begin{array}{l}0.6 \\
(0.5)\end{array}$ & $\begin{array}{l}1.9(0.7- \\
5.3)\end{array}$ & $\begin{array}{l}0.6 \\
(0.5)\end{array}$ & $1.9(0.7-5.7)$ \\
\hline
\end{tabular}

*Time in years from application year to September 2019, when data was collected. Bold values are significant at $\mathrm{p}<0.05$.

Table 4. Applicant published D\&I article between application year and July 2019 (N=102).

\begin{tabular}{|c|c|c|c|c|c|c|c|c|}
\hline & Model 1 & & Model 2 & & Model 3 & & Model & \\
\hline & $\mathrm{b}(\mathrm{SE})$ & $\begin{array}{l}\text { OR }(95 \% \\
\text { CI) }\end{array}$ & b (SE) & OR $(95 \% \mathrm{CI})$ & b (SE) & OR $(95 \% \mathrm{CI})$ & $\mathrm{b}(\mathrm{SE})$ & OR $(95 \% \mathrm{CI})$ \\
\hline \multicolumn{9}{|l|}{$\begin{array}{l}\text { MT-DIRC } \\
\quad \text { Nonfellow (ref) }\end{array}$} \\
\hline Fellow & $\begin{array}{l}1.3 \\
(0.4)\end{array}$ & $\begin{array}{l}3.8(1.7- \\
9.0)\end{array}$ & $\begin{array}{l}1.1 \\
(0.4)\end{array}$ & $3.1(1.3-7.7)$ & $1.3(0.5)$ & $3.5(1.5-8.8)$ & $\begin{array}{l}1.1 \\
(0.5)\end{array}$ & $2.9(1.2-7.5)$ \\
\hline Time & $\begin{array}{l}0.1 \\
(0.2)\end{array}$ & $\begin{array}{l}1.1(0.8- \\
1.6)\end{array}$ & $\begin{array}{l}0.1 \\
(0.2)\end{array}$ & $1.1(0.8-1.6)$ & $0.1(0.2)$ & $1.1(0.7-1.6)$ & $\begin{array}{l}0.1 \\
(0.2)\end{array}$ & $1.1(0.7-1.6)$ \\
\hline \multicolumn{9}{|l|}{ Previous D\&I publication } \\
\hline \multicolumn{9}{|l|}{ No (ref) } \\
\hline Yes & & & $\begin{array}{l}1.4 \\
(0.5)\end{array}$ & $\begin{array}{l}4.2(1.5- \\
13.1)\end{array}$ & & & $\begin{array}{l}1.4 \\
(0.6)\end{array}$ & $4.2(1.5-1.4)$ \\
\hline $\begin{array}{l}\text { Years since undergraduate } \\
\text { degree }\end{array}$ & & & & & $\begin{array}{l}-0.1 \\
(0.0)\end{array}$ & $0.93(0.86-0.99)$ & $\begin{array}{l}-0.1 \\
(0.0)\end{array}$ & $\begin{array}{l}0.93(0.86- \\
0.99)\end{array}$ \\
\hline
\end{tabular}

*Time in years from application to July 2019, when data was collected. Bold terms are significant at $\mathrm{p}<0.05$. 